\title{
Long-term results of total hip arthroplasty in developmental dysplasia of hip patients
}

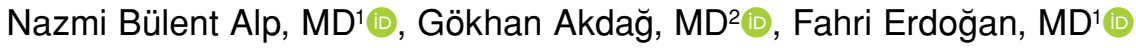 \\ ${ }^{1}$ Department of Orthopedics and Traumatology, Istanbul University, Cerrahpaşa Faculty of Medicine, Istanbul, Turkey \\ ${ }^{2}$ Department of Orthopedics and Traumatology, Istanbul Beylikdüzü State Hospital, Istanbul, Turkey
}

Developmental dysplasia of hip (DDH) is one of the well-known orthopedic pathologies that cause coxarthrosis. ${ }^{[1]}$ Pelvic bandage, traction, open or closed reduction, femoral, and pelvic osteotomies are the treatment alternatives for $\mathrm{DDH}$ in the pediatric age group. ${ }^{[2,3]}$ For end-stage osteoarthritis, total hip arthroplasty (THA) is the standard treatment. ${ }^{[4,5]}$ In the literature, several studies have reported that the anatomical hip center reconstruction yields favorable biomechanical results among those patients. ${ }^{[6,7]}$ Both acetabular and femoral abnormal anatomy make this re-establishment challenging for surgeons. Among those patients, complication rates are higher than the normal arthroplasty operations due to the pathological anatomy. In DDH patient population, changing abnormal anatomy to normal and to reduce complication rates and prolong prosthesis survival, specially designed implants are needed. In this study, we aimed to report the physiological and radiological long-term results of THA combined with or without subtrochanteric osteotomy in a group of DDH patients.

\section{PATIENTS AND METHODS}

A total of 90 hips of 59 patients ( 3 males, 56 females; mean age $45.7 \pm 10.9$ years; range, 24 to 67 years) who

Received: February 21, 2020

Accepted: March 18, 2020

Published online: June 18, 2020

Correspondence: Nazmi Bülent Alp, MD. Bursa Şehir Hastanesi Ortopedi ve Travmatoloji Kliniği, 16110 Doğanköy, Nilüfer, Bursa, Türkiye.

E-mail: nazmibulentalp@hotmail.com

Doi: $10.5606 /$ ehc. 2020.74412

Citation: Alp NB, Akdağ G, Erdoğan F. Long-term results of total hip arthroplasty in developmental dysplasia of hip patients. Jt Dis Relat Surg 2020;31(2):298-305

\section{ABSTRACT}

Objectives: This study aims to report the physiological and radiological long-term results of total hip arthroplasty (THA) combined with or without subtrochanteric osteotomy in a group of developmental dysplasia of hip (DDH) patients.

Patients and methods: This retrospective study included 90 hips of 59 patients ( 3 males, 56 females; mean age $45.7 \pm 10.9$ years; range, 24 to 67 years) who underwent THA between January 1979 and March 2006. Thirteen patients needed subtrochanteric shortening. The evaluation was performed through Harris hip scores, physical examination, and radiological imaging.

Results: The follow-up period ranged from 5 to 32 years, and the mean follow-up period was $10.3 \pm 6.4$ years. Revision was required in 17 hips out of 90 . Twelve revisions were needed because of aseptic loosening of femoral or acetabular component, three were for fracture of the femoral stem, and two for protrusio acetabuli. Four patients had transient nerve palsy, and one had permanent nerve function loss. In one patient, nonunion was observed around the femoral osteotomy site. Harris hip score was remarkably improved compared to top preoperative values (48 vs. 88.2, $\mathrm{p}<0.01)$.

Conclusion: Although revision rates tend to increase in long-term follow-up, THA is one of the best treatment options in DDH patients to relieve pain, improve daily activity levels, and minimize the damage of the knee and lumbar region.

Keywords: Crowe classification, developmental dysplasia of hip, Harris hip score, total hip arthroplasty, Trendelenburg sign.

had a final follow-up examination were included in this retrospective study. All patients were operated between January 1979 and March 2006 in the Department of Orthopedics and Traumatology, Cerrahpaşa Faculty of Medicine. Patients who did not want to participate in the study and who did not have sufficient medical records were excluded. Difficulty in carrying out daily life activities, walking challenges, and intolerable pain were indications for THA. All patients were evaluated based on Crowe's classification ${ }^{[8]}$ A total of 20 of the hips were Crowe 


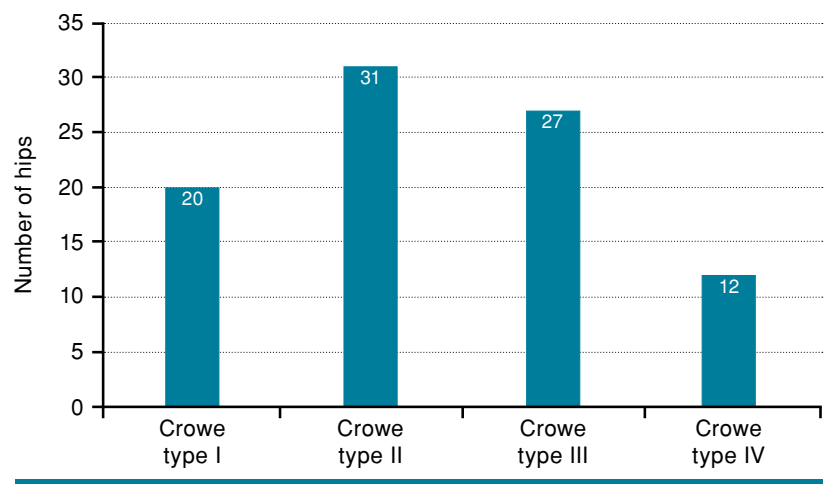

FIGURE 1. Distribution of hips according to Crowe classification. ${ }^{[8]}$

type I, 31 were Crowe type II, 27 were Crowe type III, and 12 were Crowe type IV (Figure 1). Nine patients were operated on right, 19 on left hip, while 31 were operated bilaterally. Thirteen patients needed subtrochanteric shortening osteotomy. Demographical characteristics of the patients at the last follow-up are presented in Table I. The study protocol was approved by the Istanbul University Cerrahpasa School of Medicine Ethics Committee (03 November 2010, approval no: 32721). A written informed consent was obtained from each patient. The study was conducted in accordance with the principles of the Declaration of Helsinki.

All patients were operated in a lateral decubitus position. In 87 hips, the anterolateral approach and in three hips the posterolateral approach was used. In Crowe types III and IV, because of superior migration of the hips, we raised gluteus medius and minimus muscles from the bone and reattached them posteriorly. Structural femoral head autograft with screws were used for improving coverage of the acetabular cup in nine hips. Femoral shortening with transverse or step-cut osteotomy was performed in 13 hips; the average length of the bone removed was $2.8 \mathrm{~cm}$ (range, 1 to $4 \mathrm{~cm}$ ). Since all operations were not performed by a single surgeon in this single-center study, both anatomic center and high hip center type reconstructions were performed according to the surgeon's preference (Figures 2, 3). In 58 hips, we used Morscher-Spotorno cemented stems from Protek (Sulzer Medica, Berne, Switzerland) and cemented Müller CDH components from (Zimmer, Winterthur, Switzerland). Thirty-two hips were treated with Synergy Smith \& Nephew (Smith \& Nephew, Memphis, Tennessee, USA), Corail Depuy Synthes (DePuySynthes, Warsaw, IN, USA), Wright Medical Systems Hip Replacement (Wright Medical Technology, Inc., Arlington, Tennessee, USA), and Biomet uncemented hip implants (Zimmer Biomet, Warsaw, IN, USA) (Table II).

Active range of motion exercises were initiated immediately postoperatively. Patients who did not undergo subtrochanteric osteotomy were allowed to bear full weight. In contrast, patients who underwent subtrochanteric shortening osteotomy were given toe-touch weight-bearing exercises for the first six weeks and allowed tolerable bearing after six weeks postoperatively. The Harris hip scores (HHS) and radiographs were obtained preoperatively and at

\begin{tabular}{|c|c|c|c|c|}
\hline \multicolumn{5}{|c|}{$\begin{array}{l}\text { TABLE I } \\
\text { teristics of } p\end{array}$} \\
\hline & $\mathrm{n}$ & $\%$ & Mean $\pm S D$ & Min-Max \\
\hline \multicolumn{5}{|l|}{ Gender } \\
\hline Male & 3 & 5.1 & & \\
\hline Female & 56 & 94.9 & & \\
\hline Age at surgery (year) & & & $45.7 \pm 10.9$ & $24-67$ \\
\hline Follow-up period (year) & & & $10.3 \pm 6.4$ & $5-32$ \\
\hline Follow-up period without revision (year) & & & $9.0 \pm 5.6$ & $0-25$ \\
\hline \multicolumn{5}{|l|}{ Age distribution at last follow-up (year) } \\
\hline$\leq 40$ & 9 & 10.0 & & \\
\hline $41-50$ & 12 & 13.3 & & \\
\hline $51-60$ & 16 & 17.8 & & \\
\hline $61-70$ & 16 & 17.8 & & \\
\hline$>70$ & 6 & 6.7 & & \\
\hline
\end{tabular}


regular postoperative intervals. Osteotomy site union, nerve injury, limb-length discrepancy, and component stability were assessed. Assessment of the component loosening was according to the manner described by Gruen $^{[9]}$ for the femur and DeLee and Charnley ${ }^{[10]}$ for the acetabulum. Complete loosening of the femoral stem, a change in the position of stem, migration, or collapse of more than $2 \mathrm{~mm}$, and the continuous radiolucent line between bone cement and bone were evaluated as loosening. Changes in the cup angle of more than $2^{\circ}$, vertical, and/or horizontal displacement higher than $2 \mathrm{~mm}$, and radiolucent lines wider than
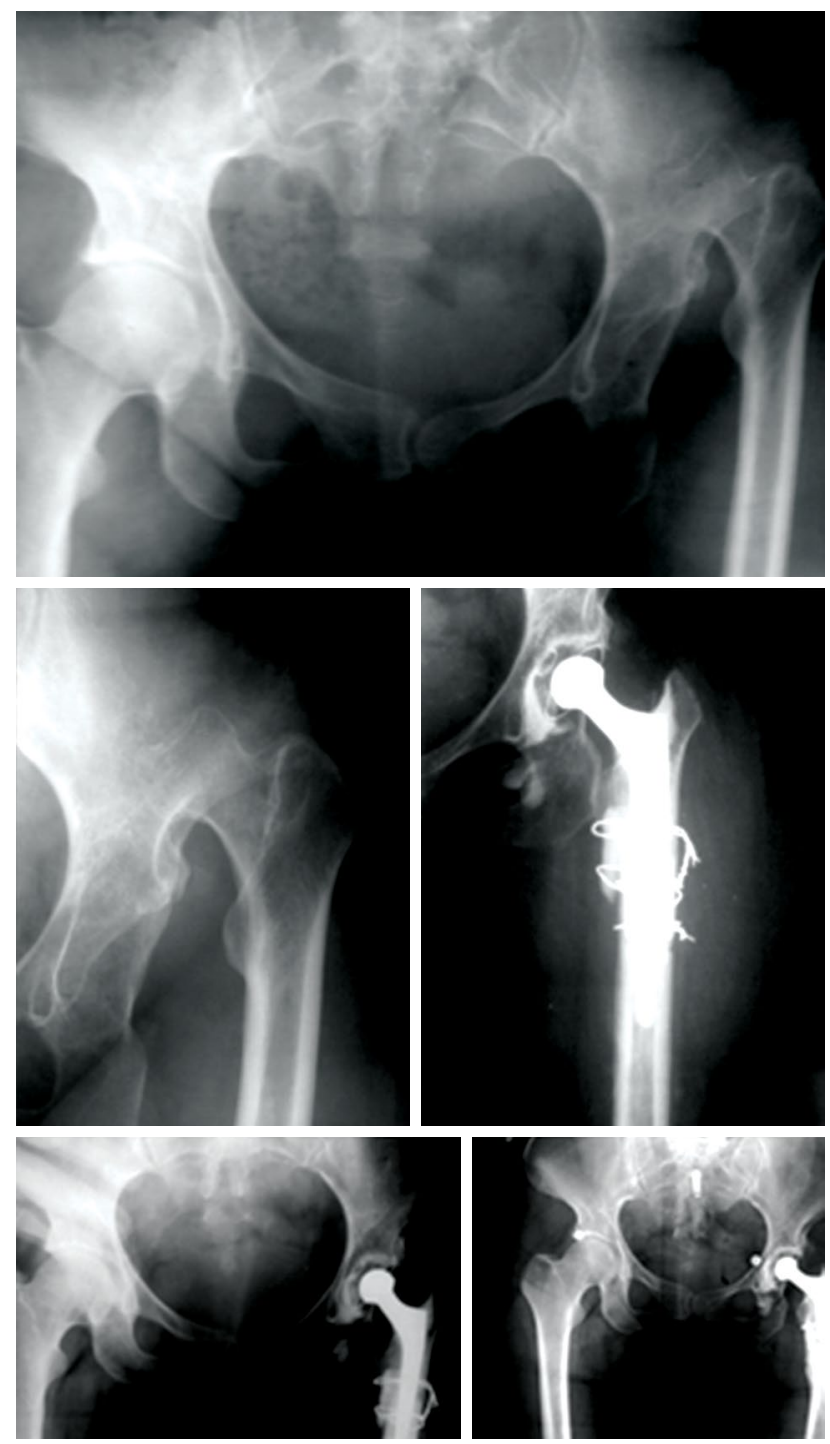

FIGURE 2. Unilateral reconstruction of Crowe type IV hip. A 41-year-old female patient treated with cemented polyethylene acetabular component, cemented femoral component with subtrochanteric step-cut femoral shortening osteotomy augmented with cerclage wiring. Union was achieved at sixth postoperative month.
$1 \mathrm{~mm}$ were evaluated in favor of acetabular component instability. Heterotopic ossification was evaluated by Brooker classification (Table III). ${ }^{[1]}$

\section{Statistical analysis}

Statistical analyses were conducted by using NCSS (Number Cruncher Statistical System) 2007 and PASS (Power analysis and sample size) 2008 statistical software (Utah, USA). Besides the descriptive statistical methods (mean, standard deviation, standard error [SE] minimum and maximum) used for the evaluation of the study data, Student's t-test was used for comparison of quantitative data of two groups with normal distribution, and paired samples t-test was used when comparing the post- and preoperational measurements within the groups. Pearson correlation coefficient was used for correlation analysis between parameters. Kaplan-Meier analysis was used for survival analysis. A $p$ value lower than 0.05 was considered as statistically significant.

\section{RESULTS}

The follow-up period ranged from 5 to 32 years with a mean follow-up period of $10.3 \pm 6.4$ years. The mean preoperative HHS was 48.0 (range, 36 to 78 ) which increased to 88.2 (range, 52.5 to 97.9) (Table IV). Subtrochanteric shortening osteotomy was performed in 13 hips and an average of $2.8 \mathrm{~cm}$ shortening was achieved (range, 1 to $4 \mathrm{~cm}$ ). Trendelenburg sign was positive in 43 of the patients in the preoperative period but remained positive in only nine of them during the postoperative period. The mean acetabular inclination angle was $47.6^{\circ}$ (range, $30^{\circ}$ to $64.4^{\circ}$ ). The vertical distance drawn from the line connecting the tear figures to the center of hip rotation was $32.2 \mathrm{~mm}$ (range, 7.9 to $65.6 \mathrm{~mm}$ ).

While $17(18.9 \%)$ of 90 prostheses were revised, $73(81.1 \%)$ were not. The mean follow-up period without revision was $19.5 \pm 1.2$ years. The last revision was observed in the year 25 . Initially, 90 patients were started, eight hip replacements were revised, and the cumulative survival rate was $90.0 \%$ with a SE of $3.4 \%$. At the end of year six, five hip prostheses were revised, and the cumulative survival rate was $78.6 \%$ with a SE of $5.56 \%$. At the end of 12 years, one more hip was revised, and the cumulative survival rate was $73.2 \%$ with a SE of $7.36 \%$. At the end of 18 years, two hip fractures occurred, and the cumulative survival rate was $56.9 \%$ with a SE of $11.6 \%$. At the end of 24 years, one more hip fracture was observed, and the cumulative survival rate decreased to $34.1 \%$ with a SE of $18.9 \%$ (Figure 4 ). 

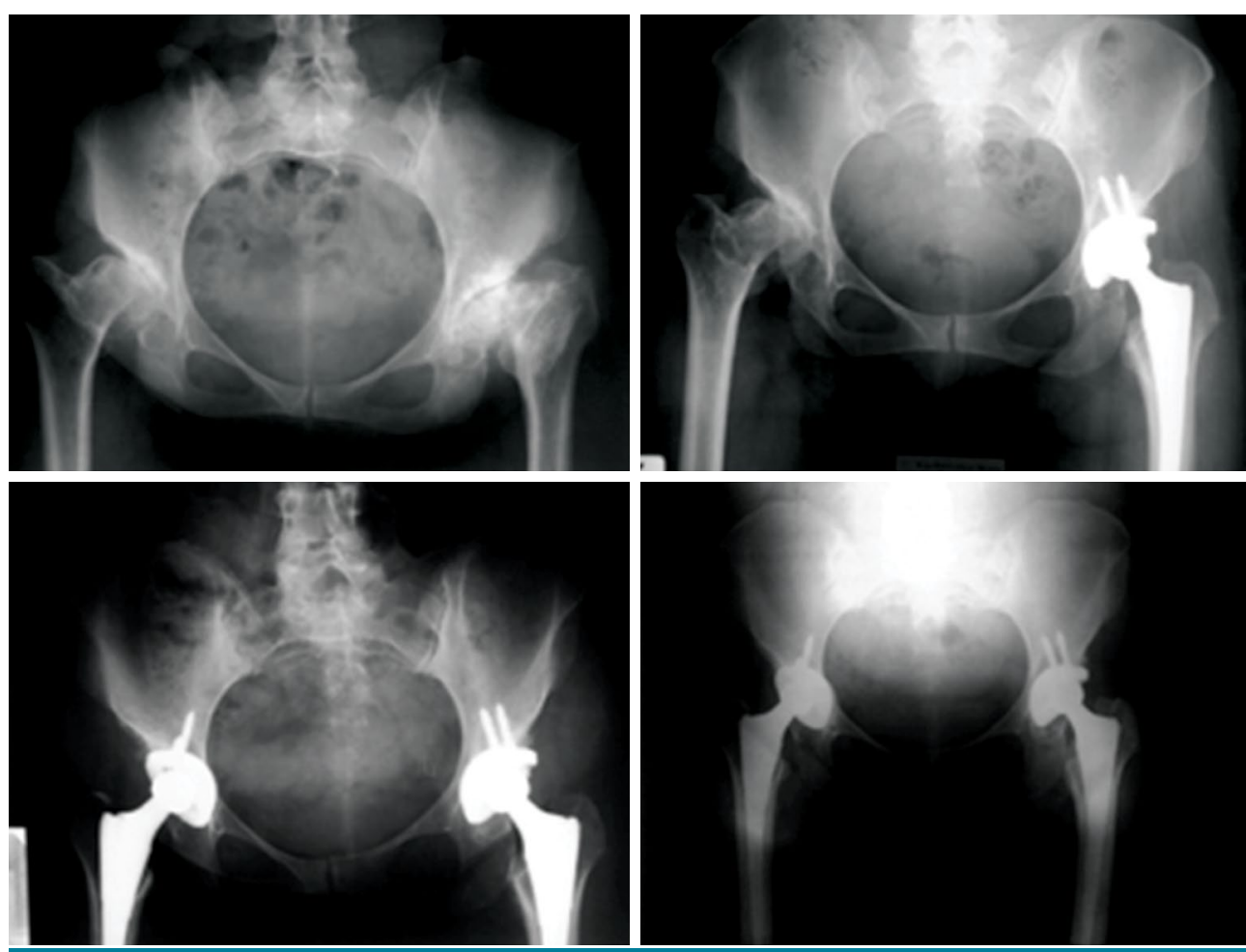

FIGURE 3. Bilateral hip dislocation of a 57-year-old female patient. Bilateral total hip arthroplasty was performed with cementless acetabulum with a cemented femoral component with polyethylene.

\section{TABLE II}

Patient characteristics and implant data for primary total hip arthroplasty in developmental dysplasia of hip patients

\begin{tabular}{|c|c|c|c|}
\hline & $\mathrm{n}$ & $\%$ & Mean $\pm S D$ \\
\hline Total number of patients & 59 & & \\
\hline Primary THAs & 90 & & \\
\hline Time to follow-up (year) & & & $10.3 \pm 6.4$ \\
\hline The average age at time of surgery (year) & & & $45.7 \pm 10.9$ \\
\hline \multicolumn{4}{|l|}{ Gender } \\
\hline Female & 56 & 95 & \\
\hline Male & 3 & 5 & \\
\hline \multicolumn{4}{|l|}{ Implant type } \\
\hline Standard & & 100 & \\
\hline Custom & & - & \\
\hline \multicolumn{4}{|l|}{ Acetabular component fixation } \\
\hline Cemented (polyethylene) & 10 & & \\
\hline Cementless (metal) & 80 & & \\
\hline \multicolumn{4}{|l|}{ Femoral component fixation } \\
\hline Cemented & 58 & & \\
\hline Cementless & 32 & & \\
\hline \multicolumn{4}{|l|}{ Bearing surface } \\
\hline Metal-on-plastic & 88 & & \\
\hline Metal-on-metal & 2 & & \\
\hline Ceramic-on-plastic & - & & \\
\hline Ceramic-on-ceramic & - & & \\
\hline
\end{tabular}




\begin{tabular}{|c|c|}
\hline & $\begin{array}{l}\text { TABLE III } \\
\text { Brooker grading of heterotopic ossification }\end{array}$ \\
\hline Grade & Degree of heterotopic bone formation \\
\hline 0 & No heterotrophic bone spurs \\
\hline I & Presence of islands of bone within the soft tissues around the hip \\
\hline II & $\begin{array}{l}\text { Presence of bone spurs originating from the proximal femur or pelvis with a distance of at least } 1 \mathrm{~cm} \text { between the } \\
\text { opposing bone surfaces }\end{array}$ \\
\hline III & $\begin{array}{l}\text { Bone spurs originating from the proximal femur or pelvis with a distance of less than } 1 \mathrm{~cm} \text { between the opposing bone } \\
\text { surfaces }\end{array}$ \\
\hline IV & Presence of bone formation connecting the proximal femur and pelvis, and the presence of prominent bone ankylosis \\
\hline
\end{tabular}

\begin{tabular}{|lccc|}
\hline \multicolumn{4}{c}{ TABLE IV } \\
Pre- and postoperative Harris hip scores \\
\hline HSS & Mean \pm SD & Min-Max & $p$ \\
\hline Preoperative & $48.0 \pm 6.0$ & $36.0-78.0$ & \\
Postoperative & $88.2 \pm 8.8$ & $52.5-97.9$ & $0.001^{*}$ \\
\hline $\begin{array}{l}\text { HHS: Harris hip score; SD: Standard } \\
\text { Max: Maximum; }{ }^{*} p<0.01 .\end{array}$ & & & \\
\hline
\end{tabular}

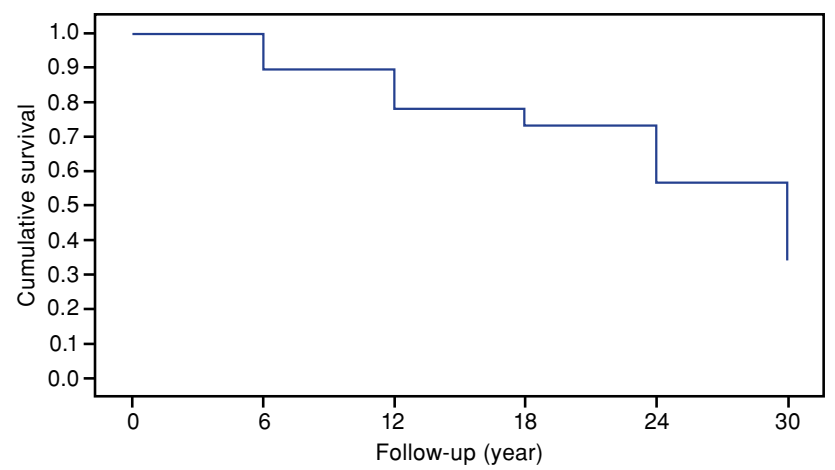

FIGURE 4. Kaplan-Meier survivorship curve of cases without revision.
Revision was required in $17(18.9 \%)$ of 90 hips which underwent THA due to DDH background. Causes of revisions were due to the aseptic loosening of the femur or acetabular component in 12 patients (6 left, 6 right hips), fracture of the prosthesis in three patients, and protrusio acetabuli in two patients. Four patients had transient nerve palsy and one had permanent nerve loss. Heterotopic ossification was observed in seven patients in our study. According to Brooker classification, one patient had grade IV (Figure 5), three patients had grade III, one patient had grade II, and two patients had grade I heterotrophic ossification. Nonunion of the femoral osteotomy site was seen in one patient.

\section{DISCUSSION}

Total hip arthroplasty is one of the best treatment options in coxarthrosis secondary to DDH to relieve pain, eliminate factors that prevent daily activities, and minimize the damage on the knee and lumbar region. However, it is challenging to operate patients with $\mathrm{DDH}$ and achieve satisfactory
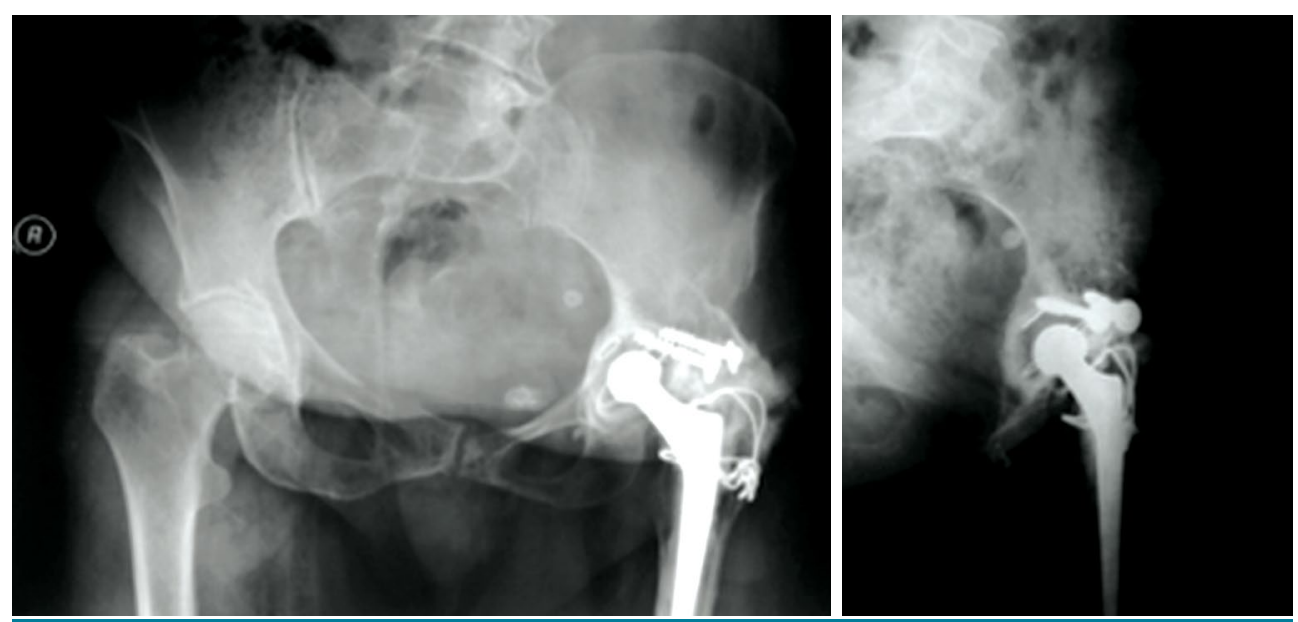

FIGURE 5. Reconstruction with structural femoral head autograft with screws. Complete heterotopic ossification occurred around left hip. 
results. Undoubtedly, the most critical step of this reconstruction surgery is the placement of the acetabular component. Some studies have shown that the placement of the acetabulum should be performed at the true acetabulum where the most significant bone stock is present. ${ }^{[12,13]}$ The acetabular cup coverage can increase by a controlled fracture of the medial acetabular wall. Controlled acetabular medialization, enlarging the acetabulum using cement, bone graft, or reinforcement cages, were described. ${ }^{[14,15]}$ Hartofilakidis et al. ${ }^{[16]}$ reported excellent results with this method in cemented cups. They reported that aseptic loosening was observed in only two of 86 dysplastic hips at a seven-year follow-up. In our patients, we performed acetabular reconstruction as much as possible, where the anatomical hip rotation center was present. We do not use the controlled break of the medial wall technique. In some cases, anatomical hip center reconstruction was needed via subtrochanteric femoral shortening osteotomy. Femoral shortening osteotomy was defined by Klisic et al., ${ }^{[17]}$ for high hip dislocations, later adapted by Sponseller and MacBeath ${ }^{[18]}$ for simultaneous hip arthroplasties. Between 1998 and 2003, Park et al. ${ }^{[19]}$ performed transverse femoral shortening osteotomy in 24 of 76 hips which were operated due to DDH. They reported that there were no neurological complications, and the mean HHS increased from 35.6 to 81.7. Yalcin et al. ${ }^{[20]}$ performed uncemented THA with subtrochanteric transverse shortening osteotomy on 44 hips of 31 patients. They obtained good-excellent results in $79.5 \%$ of patients after an average of 62-month follow-up. In 2010, Krych et al. ${ }^{[21]}$ published cementless THA combined with subtrochanteric shortening osteotomy (28 hips of 24 patients, all hips were Crowe type IV). The patients were followed-up for 4.8 years and HHS improved from 43 to 89 postoperatively. In 2011, Takao et al. ${ }^{[22]}$ published a series of 23 cementless modular THA with subtrochanteric shortening osteotomy. The mean Merle d'Aubigné-Postel scores of these patients increased from 9 to 16 . Neither nonunion nor nerve injury were experienced in Crowe type IV dislocation. Accelerated bone healing, allowing more bone contact surface, and stability properties against torsional forces are some advantages of step-cut osteotomy over transverse osteotomy. Onodera et al. ${ }^{[23]}$ found nonunion due to transverse osteotomy in 14 hips treated using modular stem. In our study, we performed subtrochanteric shortening osteotomy in 13 patients. While 12 of these patients had a complete union at the end of six months, one patient developed nonunion in the osteotomy site. In recent years, our clinic tends to switch from step-cut osteotomy to transverse osteotomy. Although step-cut osteotomy offers the above-mentioned advantages, we prefer transverse osteotomy due to its straightforward application during surgery and shortening surgical time. We try to perform acetabular reconstruction in true acetabulum position during surgery; in some cases, we preferred high hip center reconstruction due to patient's condition and risks encountered during surgery. Karaismailoglu et al. ${ }^{[24]}$ recently reported that there is no difference between high hip center reconstruction and anatomical hip center reconstruction regarding the gait analysis and high hip center reconstruction may be used during severe cases with the surgeon's preference and the patient's benefit.

The method we preferred in our long follow-up of patients was the cementless acetabular component, polyethylene, and cemented femoral stem, which is parallel to the surgical trends of that time. Later on, changes in surgical trends and an increasing number of young patients with DDH led us to use cementless acetabular and femoral components. Lai et al. ${ }^{[25]}$ performed cementless THA on 56 Crowe type IV hips. They reported no stem revision after a mean follow-up of 12.3 years.

Neurological complications were observed commonly in patients who had Crowe type III and IV hips. Edwards et al. ${ }^{[26]}$ reported that leg-lengthening significantly increased the risk of nerve lesions. The mean $2.7 \mathrm{~cm}$ and $4.4 \mathrm{~cm}$ lengthening increased the risk of the peroneal portion of the sciatic nerve injury and the risk of complete sciatic nerve injury, respectively. As a result, they stated that the lengthening should not be more than $4 \mathrm{~cm}$. Johanson et al. ${ }^{[27]}$ conducted two consecutive studies on the nerve lesions following sequential THA and found that the lesion rate was $1 \%$ in the first six years and it decreased to $0.3 \%$ in the following six years. This result was associated with the surgeon's experience. Eggli et al. ${ }^{[28]}$ evaluated eight nerve lesions (six nerve palsies, two complete injuries) following THA for 508 hips of 370 patients. There was no statistically significant relationship between lengthening and nerve injury $(p=0.47)$. However, severe deformity pattern, acetabular ceiling defect and severe flexion deformity were reported in seven of the eight patients who had undergone surgery before arthroplasty. There was a statistically significant correlation between the difficulty encountered in the operation and nerve paralysis $(\mathrm{p}=0.041)$. Eggli et al. ${ }^{[28]}$ reported that the factor causing nerve injury was direct or indirect mechanical trauma and did not associate with only leg lengthening. In the present study, 
four patients had transient nerve palsy, and one had complete nerve injury. The shortening osteotomy was not performed in two of four patients who had transient nerve palsy. Therefore, we think that the amount of lengthening is not the only factor that causes nerve lesions. Besides, we think that direct and indirect trauma is a cofactor in the mechanism of injury, as Egli et al. ${ }^{[28]}$ had mentioned.

The acetabular coverage increased by using structural femoral head autograft, and satisfactory short-term results were achieved with the cemented acetabular component. ${ }^{[29]}$ However, a high rate of failure was reported in the long-term follow-up. Shinar and Harris ${ }^{[30]}$ observed loosening in $33(60 \%)$ out of 55 patients who underwent reconstruction using the femoral head as an autograft at a mean follow-up of 16.5 years. In our study, we used the femoral head as a structural autograft in nine of 90 hips to increase acetabular coverage. Six of these hips underwent revision. Currently, we have stopped using structural femoral head autograft in DDH patients.

There are some limitations to our study. First of all, our patients were not operated with the same technique or branded prostheses. Naturally, in a single-center study, different surgeons will apply the safest method for themselves with their experience and preference. Besides, cementless femoral components were not an option in patients with DDH in the 1980s or 1990s. They were later popularized to reduce bone loss in young patients. In addition, THA results with shortening osteotomy in Crowe type III and IV hips are frequently reported while there are no long-term results covering all Crowe types. From this point of view, although this study's evaluation of all types of Crowe may be considered as a limitation, it is still a valuable study due to the limited number of publications in the literature in this regard.

In conclusion, we have determined that the longterm clinical and radiological results of THA in DDH patients are satisfactory. Although we have observed that the frequency of complication and revision rates tend to increase in Crowe type III and IV hips, THA is still one of the best treatment options in DDH patients.

\section{Declaration of conflicting interests}

The authors declared no conflicts of interest with respect to the authorship and/or publication of this article.

\section{Funding}

The authors received no financial support for the research and/or authorship of this article.

\section{REFERENCES}

1. Zeng WN, Wang FY, Chen C, Zhang Y, Gong XY, Zhou K, et al. Investigation of association between hip morphology and prevalence of osteoarthritis. Sci Rep 2016;6:23477.

2. Yilmaz G, Bakırcığlu S, Çetik RM. Effectiveness of abduction orthosis for the treatment of acetabular dysplasia. Eklem Hastalik Cerrahisi 2019;30:32-7.

3. Chiari K. Results of pelvic osteotomy as of the shelf method acetabular roof plastic. Z Orthop Ihre Grenzgeb 1955;87:14-26.

4. Charnley J, Feagin JA. Low-friction arthroplasty in congenital subluxation of the hip. Clin Orthop Relat Res 1973;91:98-113.

5. Dunn HK, Hess WE. Total hip reconstruction in chronically dislocated hips. J Bone Joint Surg [Am] 1976;58:838-45.

6. Hua WB, Yang $\mathrm{SH}, \mathrm{Xu} W \mathrm{~W}$, Ye SN, Liu XZ, Wang J, et al. Total hip arthroplasty with subtrochanteric femoral shortening osteotomy for high hip dislocation. Orthop Surg 2015;7:112-8.

7. Erdemli B, Yilmaz C, Atalar H, Güzel B, Cetin I. Total hip arthroplasty in developmental high dislocation of the hip. J Arthroplasty 2005;20:1021-8.

8. Crowe JF, Mani VJ, Ranawat CS. Total hip replacement in congenital dislocation and dysplasia of the hip. J Bone Joint Surg [Am] 1979;61:15-23.

9. Gruen TA, McNeice GM, Amstutz HC. "Modes of failure" of cemented stem-type femoral components: a radiographic analysis of loosening. Clin Orthop Relat Res 1979;141:17-27.

10. DeLee JG, Charnley J. Radiological demarcation of cemented sockets in total hip replacement. Clin Orthop Relat Res 1976;121:20-32.

11. Brooker AF, Bowerman JW, Robinson RA, Riley LH Jr. Ectopic ossification following total hip replacement. Incidence and a method of classification. J Bone Joint Surg [Am] 1973;55:1629-32.

12. Rasi AM, Kazemian G, Khak M, Zarei R. Shortening subtrochanteric osteotomy and cup placement at true acetabulum in total hip arthroplasty of Crowe III-IV developmental dysplasia: results of midterm follow-up. Eur J Orthop Surg Traumatol 2018;28:923-30.

13. $\mathrm{Wu} \mathrm{X}, \mathrm{Li} \mathrm{SH}$, Lou LM, Cai ZD. The techniques of soft tissue release and true socket reconstruction in total hip arthroplasty for patients with severe developmental dysplasia of the hip. Int Orthop 2012;36:1795-801.

14. Hess WE, Umber JS. Total hip arthroplasty in chronically dislocated hips. Follow-up study on the protrusio socket technique. J Bone Joint Surg [Am] 1978;60:948-54.

15. Woolson ST, Harris WH. Complex total hip replacement for dysplastic or hypoplastic hips using miniature or microminiature components. J Bone Joint Surg [Am] 1983;65:1099-108.

16. Hartofilakidis G, Stamos K, Ioannidis TT. Low friction arthroplasty for old untreated congenital dislocation of the hip. J Bone Joint Surg [Br] 1988;70:182-6.

17. Klisic P, Jankovic LJ, Basara V. Open reduction with pelvic osteotomy and femoral shortening. Acta Orthop Belg 1990;56:269-74.

18. Sponseller PD, McBeath AA. Subtrochanteric osteotomy with intramedullary fixation for arthroplasty of the dysplastic hip. A case report. J Arthroplasty 1988;3:351-4. 
19. Park MS, Kim KH, Jeong WC. Transverse subtrochanteric shortening osteotomy in primary total hip arthroplasty for patients with severe hip developmental dysplasia. J Arthroplasty 2007;22:1031-6.

20. Yalcin N, Kilicarslan K, Karatas F, Mutlu T, Yildirim H. Cementless total hip arthroplasty with subtrochanteric transverse shortening osteotomy for severely dysplastic or dislocated hips. Hip Int 2010;20:87-93.

21. Krych AJ, Howard JL, Trousdale RT, Cabanela ME, Berry DJ. Total hip arthroplasty with shortening subtrochanteric osteotomy in Crowe type-IV developmental dysplasia: surgical technique. J Bone Joint Surg [Am] 2010;92:176-87.

22. Takao M, Ohzono K, Nishii T, Miki H, Nakamura N, Sugano N. Cementless modular total hip arthroplasty with subtrochanteric shortening osteotomy for hips with developmental dysplasia. J Bone Joint Surg [Am] 2011;93:548-55.

23. Onodera $S$, Majima $T$, Ito $H$, Matsuno $T$, Kishimoto $T$, Minami A. Cementless total hip arthroplasty using the modular S-ROM prosthesis combined with corrective proximal femoral osteotomy. J Arthroplasty 2006;21:664-9.

24. Karaismailoglu B, Kaynak G, Can A, Ozsahin MK, Erdogan F. Bilateral high hip center provides gait parameters similar to anatomical reconstruction: a gait analysis study in hip replacement patients with bilateral developmental dysplasia. J Arthroplasty 2019;34:3099-105.

25. Lai KA, Shen WJ, Huang LW, Chen MY. Cementless total hip arthroplasty and limb-length equalization in patients with unilateral Crowe type-IV hip dislocation. J Bone Joint Surg [Am] 2005;87:339-45.

26. Edwards BN, Tullos HS, Noble PC. Contributory factors and etiology of sciatic nerve palsy in total hip arthroplasty. Clin Orthop Relat Res 1987;218:136-41.

27. Johanson NA, Pellicci PM, Tsairis P, Salvati EA. Nerve injury in total hip arthroplasty. Clin Orthop Relat Res 1983;179:214-22.

28. Eggli S, Hankemayer S, Müller ME. Nerve palsy after leg lengthening in total replacement arthroplasty for developmental dysplasia of the hip. J Bone Joint Surg $[\mathrm{Br}]$ 1999;81:843-5.

29. Harris WH. Allografting in total hip arthroplasty: in adults with severe acetabular deficiency including a surgical technique for bolting the graft to the ilium. Clin Orthop Relat Res 1982;162:150-64.

30. Shinar AA, Harris WH. Bulk structural autogenous grafts and allografts for reconstruction of the acetabulum in total hip arthroplasty. Sixteen-year-average follow-up. J Bone Joint Surg [Am] 1997;79:159-68. 